\title{
Management of atrial fibrillation by primary care physicians in Germany: baseline results of the ATRIUM registry
}

\author{
Thomas Meinertz • Wilhelm Kirch • \\ Ludger Rosin • David Pittrow $\cdot$ Stefan N. Willich • \\ Paulus Kirchhof $\cdot$ for the ATRIUM investigators
}

Received: 7 December 2010/Accepted: 12 April 2011/Published online: 1 May 2011

(C) The Author(s) 2011. This article is published with open access at Springerlink.com

\begin{abstract}
Background In contrast to surveys in cardiologist settings, presentation and management of atrial fibrillation (AF) in primary care patients is less well studied.

Methods and results The prospective ATRIUM (Outpatient Registry Upon Morbidity of Atrial Fibrillation) collected data from patients with AF seen by 730 physicians representing a random sample of all primary care physicians in Germany. ATRIUM enrolled 3,667 patients (mean age, $72 \pm 9$ years; $58 \%$ male, mean $\mathrm{CHADS}_{2}$ score $2.2 \pm 1.3), 994(27.1 \%)$ with paroxysmal, $944(25.7 \%)$ with persistent or long-standing persistent and 1,525
\end{abstract}

The ATRIUM registry was compiled by Sanofi-Aventis, Germany in cooperation with the German Atrial Fibrillation NETwork (AFNET).

T. Meinertz

Klinik und Poliklinik für Allgemeine und Interventionelle

Kardiologie, Universitäres Herzzentrum Hamburg,

Hamburg, Germany

W. Kirch · D. Pittrow

Institut für Klinische Pharmakologie, Medizinische Fakultät,

Technische Universität, Dresden, Germany

L. Rosin

Medizinische Abteilung, Sanofi-Aventis Deutschland GmbH,

Berlin, Germany

S. N. Willich

Institut für Sozialmedizin, Epidemiologie und

Gesundheitsökonomie, Charité, Berlin, Germany

P. Kirchhof $(\square)$

Department of Cardiology and Angiology,

University Hospital Münster, Albert-Schweitzer-Straße 33,

48149 Münster, Germany

e-mail:kirchhp@uni-muenster.de
(41.6\%) with permanent AF (no AF type was specified in 204 patients). Mean duration since initial diagnosis of $\mathrm{AF}$ was $61 \pm 66$ months (median 42, interquartile range 14-88). Reported symptoms included palpitations (43\%), shortness of breath (49\%), fatigue (49\%), dizziness (37\%) and angina (20\%). Most common concomitant conditions were hypertension $(84 \%)$, heart failure $(43 \%)$, coronary artery disease (345\%), diabetes (35\%) and chronic kidney disease (20\%). Prior myocardial infarction was present in $11 \%$ of patients, prior stroke in $10 \%$ and prior transient ischemic attack in $10 \%$. Antithrombotic medication was used by $93 \%$ of the patients (oral anticoagulants, $83 \%$ ). Rate control therapy was reported in $75 \%$ and rhythm control therapy in 33\%, often added to rate control. Drugs for rhythm and rate control included B-blockers (75\%), calcium antagonists (15\%), digitalis (29\%), sodium channel blockers of type IA (quinidine, 1.0\%) or IC (flecainide or propafenone, $5 \%$ ), and potassium channel blockers including amiodarone (11\%). In the year prior to enrollment, $46 \%$ of the patients had been cardioverted ( $23 \%$ by drugs, $22 \%$ electrically), catheter ablation had been performed in $5 \%$, and $10 \%$ received a pacemaker or defibrillator. A high proportion (44\%) of the patients were hospitalized in the year prior to enrollment.

Conclusions Patients with AF managed in primary care often receive guideline-conforming therapy including antithrombotic therapy, rate control and rhythm control (numbers given above). Despite this apparent adherence, almost half of the patients were hospitalized in the year prior to enrollment, suggesting that the therapies applied do not stabilize patients sufficiently to keep them out of hospital.

Keywords Atrial fibrillation - Management . Anticoagulation · Survey · Therapy 


\section{Background}

Atrial fibrillation (AF) is the most commonly sustained arrhythmia and affects at least $1 \%$ of the population in Germany [1]. AF prevalence increases markedly with age, resulting in an estimated two- to threefold increase in AF patients in the next two decades [6, 31]. Many AF patients suffer from concomitant conditions including hypertension, vascular disease, heart failure and diabetes mellitus among others. In addition to variable but often relevant symptoms, AF appears to cause every fourth to fifth stroke and is associated with a doubling of mortality [34, 36].

AF management therefore consists of antithrombotic therapy, which is guided by clinical stroke risk estimation [1, 21], rate control therapy to improve left ventricular function and symptoms during $\mathrm{AF}$, and rhythm control therapy to prevent AF recurrences. Despite the widely perceived notion that AF may cause severe complications, rhythm control therapy using common drugs does not prevent deaths in AF patients $[11,26,33,39]$, resulting in recommendations that rhythm control therapy should be pursued in patients who remain symptomatic on rate control [1].

Based on the variable presentation of AF and on slightly differing recommendations in clinical practice, differences in $\mathrm{AF}$ management depending on the type of treating physician can be expected [24]. Unfortunately, most registry data so far report that most AF patients are managed by cardiologists or other specialists.

We therefore initiated the prospective German ATRIUM registry to characterize $\mathrm{AF}$ management in patients treated by primary care physicians. Here, we report the baseline observations of this registry.

\section{Methods}

Design ATRIUM (Outpatient Registry Upon Morbidity of Atrial Fibrillation) is a prospective, multicenter, epidemiological, non-interventional cohort study. ATRIUM enrolled 3,667 patients in 730 primary care practices in Germany in 2009. Baseline data included current management and information on interventions and complications in the year prior to enrollment. This data set is reported here. The ethics committee of the Technical University Dresden approved the study protocol. All patients gave written consent prior to enrollment.

To draw a random sample of centers, a multi-step procedure was used in which more than 25,000 physicians were contacted (Department of Medical Informatics, Biometry and Epidemiology, University of Bochum). Based on a comprehensive nationwide database of physicians (Schwarzeck-Verlag), a representative sample of 25,000 primary care physicians was drawn by Abteilung für Medizinische Informatik, Biometrie und Epidemiologie, Ruhr-Universität Bochum. These physicians were contacted via letter and informed about the study, and the first 730 respondents were offered participation. The centers agreed to consecutively enroll patients with AF documented by ECG in the 12 months prior to enrollment. No exclusion criteria were defined to minimize selection bias. All data were recorded during an outpatient visit and included information from the patient charts.

Parameters The following baseline parameters were documented: age, sex, body weight, height, blood pressure, risk factors for cardiovascular disease, cardiac history and concomitant diseases. The CHADS2 score was specifically recorded and the $\mathrm{CHA}_{2} \mathrm{D}_{2} \mathrm{SVASc}$ score, which was recently proposed as a refinement of the $\mathrm{CHADS}_{2}$ score [1], was computed using the available information. In addition, we recorded the month of initial diagnosis of AF, type of AF (paroxysmal, persistent including long-lasting persistent, or permanent), type of diagnostic tests performed, suspected triggering factors of AF, therapy in the year prior to enrollment, hospitalizations in the year prior to enrollment and referral to a specialist. Drugs were recorded by drug class. Quality of life was assessed by EQ-5D in its validated German version [9].

\section{Data analysis and statistics}

All data were recorded on paper case report forms (CRF), and double-entered by a contract research organization (CRO Dr. Schauerte, Grünwald) into the study database.

A prespecified validation plan was used to check for plausibility. Analysis was done by SAS Institute Inc., version 9.2 (Cary, NC, USA). Continuous parameters are given as means \pm standard deviation and categorical parameters as the number of patients and percentages. Continuous parameters were compared between groups using ANOVA, and non-continuous parameters were compared using chi-square test. Throughout the paper, twosided $p$ values are given.

\section{Results}

Enrolling centers Of the 730 enrolling physicians $(65 \%$ males), $63 \%$ were primary care phsyicians ("Facharzt für Allgemeinmedizin"), 34\% internists with a license and practice in primary care ("Internist in hausärztlicher Praxis") and 4\% practising physicians. Practices were distributed among cities (29\%), small towns (30\%) and in rural areas $(40 \%$, data not recorded in $0.7 \%$ ) Enrolling physicians were $50 \pm 8$ years old and worked in their practice for an average of $14 \pm 9$ years or in a polyclinic ("Medizinisches Versorgungszentrum") for $9 \pm 11$ years. 
Patient characteristics ATRIUM enrolled 3,667 patients, $58 \%$ male, with a mean age of $72 \pm 9$ years; $80 \%$ of the patients were retired (Table 1). The mean age was higher in patients with permanent AF than in those with paroxysmal $\mathrm{AF}$, most likely reflecting the progressive nature of $\mathrm{AF}$ and the fact that older age was one of the factors that favored rate control therapy [1]. Paroxysmal AF was present in 994 (26\%) patients, persistent including long-standing persistent AF in $944(27 \%)$ and permanent AF in 1,525 (42\%); in 204 patients $(6 \%)$, AF type was not specified. Mean duration since the initial diagnosis of AF was $61 \pm 66$ months (median 42, interquartile range, 14-88).

The mean $\mathrm{CHADS}_{2}$ score was $2.2 \pm 1.3$. The mean $\mathrm{CHA}_{2} \mathrm{DS}_{2} \mathrm{VASC}$ score was $3.8 \pm 1.7$. $\mathrm{CHA}_{2} \mathrm{DS}_{2} \mathrm{VASC}$ score was lower in patients with paroxysmal AF $(3.4 \pm 1.7)$ compared to persistent AF (3.7 \pm 1.6$)$ or permanent AF (4.1 \pm 1.7$)$. Categorical distribution of scores is shown in Fig. 1.

Reported symptoms included palpitations (43\%), shortness of breath (49\%), fatigue (49\%), dizziness (37\%) and angina (20\%). Most common concomitant conditions were hypertension $(84 \%)$, heart failure $(43 \%)$, coronary artery disease $(35 \%)$, diabetes $(35 \%)$ and chronic renal dysfunction $(20 \%)$. Patients with a higher number of risk factors were more frequent in the groups with permanent AF (Fig. 2). Prior myocardial infarction was present in $11 \%$, prior stroke in $10 \%$ and prior transient ischemic attack in $10 \%$.

Therapeutic goals Enrolling physicians reported the following therapeutic goals: prevention of thromboembolic events $(77 \%)$, prevention of hospitalizations $(57 \%)$, reduction of cardiovascular mortality $(61 \%)$, rate control (76\%) and rhythm control (33\%; Table 2).

AF management Antithrombotic medication was used by $93 \%$ of the patients (oral anticoagulants $83 \%$, antiplatelet drugs 27\%, heparin 4\%; Table 3). Contraindications for oral anticoagulants were reported in $6.4 \%$. Of the 3,667 patients, 262 had $\mathrm{CHADS}_{2}$ score 0 and 79 $\mathrm{CHA}_{2} \mathrm{DS}_{2}$-VASc score 0 and were therefore rated as not eligible for $\mathrm{OAC} ; 900\left(\mathrm{CHADS}_{2}\right)$ and $240\left(\mathrm{CHA}_{2} \mathrm{DS}_{2^{-}}\right.$ VASc) patients had a score of 1 and were potentially eligible; 2,486 $\left(\mathrm{CHADS}_{2}\right)$ had a score $\geq 2$ and thus were eligible for OAC for anticoagulation according to the guidelines in place at the time of the survey. [5, 28] Many patients received $\mathrm{OAC}$ despite being not eligible according to the scores (Fig. 3a, b). Further, of the 3,667 patients, 3,329 patients had a $\mathrm{CHA}_{2} \mathrm{DS}_{2}$-VASc score of 2 or more, rendering approximately $90 \%$ of the surveyed patients eligible for oral anticoagulation according to current recommendations [1]. Most patients at risk for stroke were adequately anticoagulated (Fig. 2) and, especially in patients without an indication for anticoagulation according to $\mathrm{CHADS}_{2}$ score, over-anticoagulation was also found (Fig. 2).
A total of 2,738 patients $(75 \%)$ received rate control therapy, while $16 \%$ received rhythm control therapy either alone (189 patients; 5\%) or in combination (404 patients; $11 \%)$. Drugs for rhythm and rate control included betablockers $(75 \%)$, calcium antagonists (15\%), digitalis (29\%), potassium channel blockers including amiodarone (11\%), and sodium channel blockers of the type IA (usually quinidine, $1.0 \%$ ) or IC (usually flecainide or propafenone, $5 \%$ ). In the year prior to enrollment, $46 \%$ of the patients had been cardioverted ( $23 \%$ by drugs and $22 \%$ electrically; Table 4). Catheter ablation had been performed in 5\%, and $10 \%$ received a pacemaker or defibrillator.

A total of 1,602 patients $(44 \%)$ were hospitalized in the year prior to enrollment, with 772 patients having been hospitalized more than once (Table 5). The mean hospitalization rates were somewhat higher for paroxysmal and persistent AF compared to permanent AF (1.2 vs. 1.1 vs. 0.7 stays during 1 year).

In the surveyed period, only $41 \%$ of the patients fulfilled the criteria for stable disease, defined as stable medication without AF-associated interventions.

Quality of life The EQ-5D was obtained from 3,460 patients. The mean EQ-5D index was $0.86 \pm 0.19$, close to the maximum value of 1 . The corresponding VAS, in contrast, showed a mean value of $67 \pm 18$, indicating reduced quality of life.

\section{Discussion}

The data from ATRIUM described here provide information on the type of AF management in a sample of patients in primary care collected through a random sample of primary care physicians. Thereby, the report fills an information gap, as most prior registries include predominantly patients managed by cardiologists and/or in hospitals [2, 4, 17, 24, 27], which likely induced a selection bias based on center selection. Another registry, similar to ATRIUM, enrolled patients managed by German cardiologists [14]. Other information is available from populationwide samples [3, 6-8, 12, 13, 16, 30, 34, 35, 37], but information on the large proportion of patients managed as outpatients in primary care is scarce [19, 20, 22]. The central registry of the Germany AFNET more closely reflects the situation of $\mathrm{AF}$ patients managed by different types of physicians through enrollment of almost 10,000 patients from different levels of care [15, 23]. But even in the AFNET registry, only 811 patients were enrolled by primary care physicians $(9 \%)$, demonstrating the need for further data from this sector of health care [23].

Classification ATRIUM enrolled a large unselected cohort of outpatients with AF in different stages of their disease (paroxysmal, persistent and permanent). We did 
Table 1 Patient characteristics

\begin{tabular}{|c|c|c|c|c|c|c|c|}
\hline & \multirow{2}{*}{\multicolumn{2}{|c|}{$\begin{array}{l}\text { Paroxysmal } \\
n=994\end{array}$}} & \multirow{2}{*}{\multicolumn{2}{|c|}{$\begin{array}{l}\text { Persistent } \\
n=944\end{array}$}} & \multirow{2}{*}{\multicolumn{2}{|c|}{$\frac{\text { Permanent }}{n=1,525}$}} & \multirow{3}{*}{$\begin{array}{l}\text { Tests }^{\#} \\
p\end{array}$} \\
\hline & & & & & & & \\
\hline & $n$ & Value & $n$ & Value & $n$ & Value & \\
\hline \multicolumn{8}{|l|}{ Demographics } \\
\hline Age (years) & & $69.8 \pm 9.9$ & & $71.4 \pm 9.1$ & & $73.7 \pm 8.4$ & $<0.0001$ \\
\hline$>65$ years & 725 & 72.9 & 729 & 77.2 & 1,307 & 85.7 & $<0.0001$ \\
\hline Male & 565 & 56.8 & 564 & 59.7 & 891 & 58.4 & 0.4435 \\
\hline Body mass index $\left(\mathrm{kg} / \mathrm{m}^{2}\right)$ & & $28.4 \pm 4.6$ & & $28.8 \pm 4.8$ & & $28.6 \pm 4.8$ & $0.0851^{\$}$ \\
\hline Overweight & 468 & 47.1 & 440 & 46.6 & 702 & 46.0 & 0.2291 \\
\hline Obese & 300 & 30.2 & 324 & 34.3 & 488 & 32.0 & \\
\hline \multicolumn{8}{|l|}{ Occupational status } \\
\hline Occupied & 150 & 15.1 & 102 & 10.8 & 89 & 5.8 & $<0.0001$ \\
\hline Retired & 731 & 73.5 & 733 & 77.6 & 1,293 & 84.8 & \\
\hline Prematurely retired & 55 & 5.5 & 53 & 5.6 & 68 & 4.5 & \\
\hline Other & 54 & 5.4 & 55 & 5.7 & 72 & 4.8 & \\
\hline \multicolumn{8}{|l|}{ Risk factors } \\
\hline Arterial hypertension & 818 & 82.3 & 799 & 84.6 & 1,277 & 83.7 & 0.3875 \\
\hline Hyperlipidemia & 611 & 61.5 & 574 & 60.8 & 912 & 59.8 & 0.7932 \\
\hline Diabetes mellitus & 297 & 29.9 & 314 & 33.3 & 599 & 39.3 & $<0.0001$ \\
\hline Smoking status & & & & & & & 0.3971 \\
\hline Never & 571 & 57.4 & 509 & 53.9 & 821 & 53.8 & \\
\hline Previously & 368 & 37.0 & 376 & 39.8 & 614 & 40.3 & \\
\hline Currently & 50 & 5.0 & 55 & 5.8 & 87 & 5.7 & \\
\hline Hyperthyreosis & 55 & 5.5 & 55 & 5.8 & 91 & 6.0 & 0.9508 \\
\hline Alcohol abuse & 32 & 3.2 & 48 & 5.1 & 60 & 3.9 & 0.1271 \\
\hline \multicolumn{8}{|l|}{ Concomitant diseases } \\
\hline Chronic kidney disease & 167 & 16.8 & 179 & 19.0 & 335 & 22.0 & 0.0051 \\
\hline Dialysis & 1 & 0.6 & 1 & 0.6 & 4 & 1.2 & 0.6903 \\
\hline Serum creatinine $(\mathrm{mg} / \mathrm{dl})$ & & $1.4 \pm 0.5$ & & $1.3 \pm 0.5$ & & $1.4 \pm 0.6$ & 0.1850 \\
\hline Creatinine clearance $(\mathrm{ml} / \mathrm{min})$ & & $53.9 \pm 20.9$ & & $56.6 \pm 21.4$ & & $56.5 \pm 18.1$ & 0.7005 \\
\hline Transitory ischemic attack & 105 & 10.6 & 83 & 8.8 & 158 & 10.4 & 0.3434 \\
\hline Prior stroke & 101 & 10.2 & 82 & 8.7 & 160 & 10.5 & 0.3254 \\
\hline Ischemic & 81 & 80.2 & 62 & 75.6 & 127 & 79.4 & 0.8450 \\
\hline Hemorrhagic & 7 & 6.9 & 4 & 4.9 & 7 & 4.4 & \\
\hline \multicolumn{8}{|l|}{ Cardiac risk factors/conditions } \\
\hline Coronary artery disease & 302 & 30.4 & 315 & 33.4 & 587 & 38.5 & $<0.0001$ \\
\hline Myocardial infarction & 98 & 9.9 & 102 & 10.8 & 186 & 12.2 & 0.1345 \\
\hline PTCA & 161 & 16.2 & 160 & 16.9 & 244 & 16.0 & 0.9075 \\
\hline Chronic heart failure & 297 & 29.9 & 399 & 42.3 & 790 & 51.8 & $<0.0001$ \\
\hline \multicolumn{8}{|l|}{ Highest NYHA stage in history } \\
\hline I & 36 & 12.1 & 55 & 13.8 & 104 & 13.2 & 0.5018 \\
\hline II & 107 & 36.0 & 153 & 38.3 & 323 & 40.9 & \\
\hline III & 95 & 32.0 & 130 & 32.6 & 243 & 30.8 & \\
\hline IV & 36 & 12.1 & 37 & 9.3 & 66 & 8.4 & \\
\hline \multicolumn{8}{|l|}{ Current NYHA stage } \\
\hline I & 111 & 37.4 & 147 & 36.8 & 292 & 37.0 & 0.8135 \\
\hline II & 142 & 47.8 & 207 & 51.9 & 386 & 48.9 & \\
\hline III & 39 & 13.1 & 43 & 10.8 & 104 & 13.2 & \\
\hline IV & 1 & 0.3 & 1 & 0.3 & 5 & 0.6 & \\
\hline
\end{tabular}


Table 1 continued

\begin{tabular}{|c|c|c|c|c|c|c|c|}
\hline & \multicolumn{2}{|c|}{ Paroxysmal } & \multicolumn{2}{|c|}{ Persistent } & \multicolumn{2}{|c|}{ Permanent } & \multirow[t]{2}{*}{ Tests $^{\#}$} \\
\hline & \multicolumn{2}{|c|}{$n=994$} & \multicolumn{2}{|c|}{$n=944$} & \multicolumn{2}{|c|}{$n=1,525$} & \\
\hline & $n$ & Value & $n$ & Value & $n$ & Value & $p$ \\
\hline \multicolumn{8}{|l|}{$\mathrm{AF}$} \\
\hline Atrial fibrillation & 911 & 91.6 & 884 & 93.6 & 1,488 & 97.6 & $<0.0001$ \\
\hline Atrial flutter & 72 & 7.2 & 63 & 6.7 & 24 & 1.6 & $<0.0001$ \\
\hline $\mathrm{CHADS}_{2}$ score & & $1.9 \pm 1.2$ & & $2.1 \pm 1.2$ & & $2.4 \pm 1.3$ & $<0.0001$ \\
\hline $\mathrm{CHA}_{2} \mathrm{DS}_{2}$-VASc & & $3.4 \pm 1.7$ & & $3.7 \pm 1.6$ & & $4.1 \pm 1.7$ & $<0.0001$ \\
\hline
\end{tabular}

\# $\chi^{2}$-test or $F$ test for analysis of variance (ANOVA)

$\S$ Nonparametric Kruskal-Wallis test, $p=0.0415$

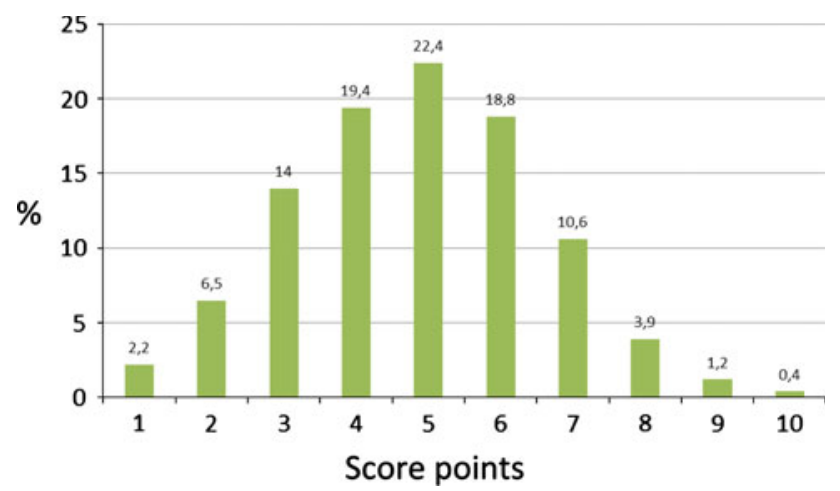

Fig. $1 \mathrm{CHA}_{2} \mathrm{DS}_{2}$-VASc score. Score points based on available data for the calculation of the score in 3,667 patients

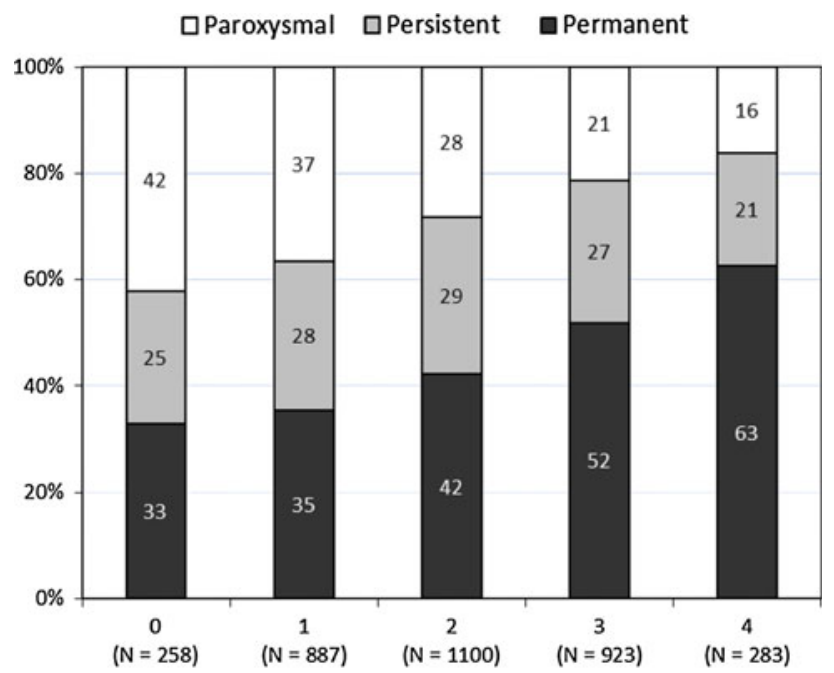

Number of concomitant conditions

Fig. 2 Numbers of concomitant conditions, by AF type. Risk factors: age $\geq 75$ years, arterial hypertension, diabetes mellitus and chronic heart failure. Values are missing for AF type in 204 patients and for concomitant conditions in 18 patients

not differentiate between first diagnosed $\mathrm{AF}$ and other forms of $\mathrm{AF}$ in this setting, as the classification "first diagnosed $\mathrm{AF}$ " is more relevant in acute settings such as emergency rooms or hospitals, as reflected by the rates of first diagnosed AF in the ALFA (26\%) [19], Euro Heart Survey (18\%) [24] and AFNET [23] (11\%) registries.

Patient characteristics in relation to other registries Consistent with the expected flow of management in which patients with AF may be initially seen by a specialist, but later continue their treatment in primary care [1], mean age in ATRIUM (72 years) was higher than in the Euro Heart Survey (69 \pm 10 years) or the AFNET registry (67 \pm 13 years), and mean AF duration was over 5 years (66 months). Males slightly outnumbered females, comparable to other surveys. As expected, concomitant conditions were common, but there were slight differences: arterial hypertension was more often found in ATRIUM than in Euro Heart Survey (64\%) or AFNET registries (69\%). Also, coronary artery disease was surprisingly prevalent when compared with the aforementioned surveys $[23,24]$. Similar to the AFNET registry, permanent AF was associated with more concomitant conditions.

Therapy and interventions In ATRIUM, $46 \%$ of the patients underwent cardioversion in the year prior to enrollment. Half of all cardioversions (23\% of the total patient cohort) were achieved by drugs, which represents a higher rate than in MOVE (18\%) [14], the AFNET registry (3-16\% depending on the AF type) [23] or the Euro Heart Survey (3-14\% depending on AF type) [24]. Electrical cardioversion was also relatively frequent in ATRIUM (22\% in the total AF cohort) compared to AFNET (7-23\% depending on AF type), MOVE (18\%), or the Euro Heart Survey (3-24\%) [14, 23] [24].

The type of rate control therapy was not markedly different from other trials and registries, with the exception of slightly lower use of digitalis glycosides, potentially already reflecting the growing experience that these agents only control heart rate well in sedentary patients [14, 23].

In ATRIUM, almost all patients received (any) antithrombotic therapy $(92.5 \%)$, suggesting that stroke prevention was a firmly established therapeutic goal in the 
Table 2 Goals of therapy

\begin{tabular}{|c|c|c|c|c|c|c|c|}
\hline & \multicolumn{2}{|c|}{ Paroxysmal } & \multicolumn{2}{|c|}{ Persistent } & \multicolumn{2}{|c|}{ Permanent } & \multirow{3}{*}{$\begin{array}{l}\text { Tests }^{\#} \\
p\end{array}$} \\
\hline & \multicolumn{2}{|c|}{$n=994$} & \multicolumn{2}{|c|}{$n=944$} & \multicolumn{2}{|c|}{$n=1,525$} & \\
\hline & $n$ & $\%$ & $n$ & $\%$ & $n$ & $\%$ & \\
\hline Prevention of thrombo-embolic complications & 718 & 72.2 & 728 & 77.1 & 1,238 & 81.2 & $<0.0001$ \\
\hline Prevention of hospitalizations & 537 & 54.0 & 524 & 55.5 & 943 & 61.8 & $<0.0001$ \\
\hline Reduction of cardiovascular mortality & 553 & 55.6 & 568 & 60.2 & 1,020 & 66.9 & $<0.0001$ \\
\hline Rhythm control & 623 & 62.7 & 336 & 35.6 & 205 & 13.4 & $<0.0001$ \\
\hline Rate control & 596 & 60.0 & 722 & 76.5 & 1,301 & 85.3 & $<0.0001$ \\
\hline Other & 52 & 5.2 & 65 & 6.9 & 81 & 5.3 & 0.1961 \\
\hline
\end{tabular}

Percentages did not sum up to $100 \%$ because multiple answers were possible

\# $\chi^{2}$-test

Table 3 Therapy in the previous 12 months

\begin{tabular}{|c|c|c|c|c|c|c|c|}
\hline & \multicolumn{2}{|c|}{ Paroxysmal } & \multicolumn{2}{|c|}{ Persistent } & \multicolumn{2}{|c|}{ Permanent } & \multirow{3}{*}{$\begin{array}{l}\text { Tests }^{\#} \\
p\end{array}$} \\
\hline & \multicolumn{2}{|c|}{$n=994$} & \multicolumn{2}{|c|}{$n=944$} & \multicolumn{2}{|c|}{$n=1,525$} & \\
\hline & $n$ & Value & $n$ & Value & $n$ & Value & \\
\hline \multicolumn{8}{|l|}{ Antiarrhythmic drugs class } \\
\hline IA & 13 & 1.3 & 13 & 1.4 & 7 & 0.5 & 0.0273 \\
\hline Duration (months) & & $9.4 \pm 4.4$ & & $10.2 \pm 3.1$ & & $9.3 \pm 4.4$ & 0.8008 \\
\hline IC & 107 & 10.8 & 46 & 4.9 & 27 & 1.8 & $<0.0001$ \\
\hline Duration (months) & & $9.0 \pm 4.1$ & & $7.0 \pm 4.7$ & & $9.5 \pm 4.3$ & $<0.0001$ \\
\hline II & 754 & 75.9 & 724 & 76.7 & 1,112 & 72.9 & 0.0122 \\
\hline Duration (months) & & $10.1 \pm 3.4$ & & $9.8 \pm 3.7$ & & $11.5 \pm 1.9$ & $<0.0001$ \\
\hline III & 140 & 14.1 & 119 & 12.6 & 112 & 7.3 & $<0.0001$ \\
\hline With ß-blocker activity & 54 & 5.4 & 52 & 5.5 & 76 & 5.0 & 0.7330 \\
\hline Duration (months) & & $8.9 \pm 4.4$ & & $9.3 \pm 3.7$ & & $10.5 \pm 3.3$ & 0.0593 \\
\hline Other & 83 & 8.4 & 65 & 6.9 & 35 & 2.3 & $<0.0001$ \\
\hline Duration (months) & & $7.8 \pm 4.4$ & & $6.7 \pm 4.4$ & & $9.6 \pm 3.3$ & 0.0052 \\
\hline IV & 130 & 13.1 & 140 & 14.8 & 273 & 17.9 & 0.0046 \\
\hline Duration (months) & & $9.8 \pm 3.9$ & & $9.8 \pm 3.6$ & & $11.5 \pm 1.9$ & $<0.0001$ \\
\hline Digitalis & 204 & 20.5 & 262 & 27.8 & 547 & 35.9 & $<0.0001$ \\
\hline Duration (months) & & $9.4 \pm 4.0$ & & $8.8 \pm 4.1$ & & $11.3 \pm 2.3$ & $<0.0001$ \\
\hline
\end{tabular}

$\# \chi^{2}$-test or $F$ test for analysis of variance (ANOVA)

primary care setting. Furthermore, over $70 \%$ of patients with an evidence-based indication for oral anticoagulation received such therapy, a high proportion compared to other surveys. [38] Consistent with other registries [23, 25], a substantial portion of patients potentially ineligible for oral anticoagulation received such therapy (Fig. 3). This may in part reflect the "subconscious" application of a broader indication of anticoagulation in AF patients, as formalized in the $\mathrm{CHA}_{2} \mathrm{DS}_{2} \mathrm{VASc}$ score $[1,21]$. Furthermore, the parameter "vascular disease" was somewhat underreported in this survey, as the components atherosclerosis of the aorta and peripheral arterial disease, were not recorded in the CRF
Frequent hospitalizations despite enrollment of presumably "stable" patients The outpatient setting of ATRIUM also resulted in a high proportion of patients with permanent AF (42\%, more than in Euro Heart Survey (29\%) or AFNET (33\%)), consistent with the AFNET data set showing a higher proportion of patients with permanent AF in outpatient centers [23]. The mean hospitalization rates were higher in paroxysmal and persistent AF compared to permanent $\mathrm{AF}$, which is in contrast to earlier findings in the COCAF study [18]. Despite relatively frequent hospitalizations, the mean quality of life score in ATRIUM was slightly better than in the Euro Heart Survey (EQ-5D men 0.85, women 0.73) [24]. The outpatient setting and the 


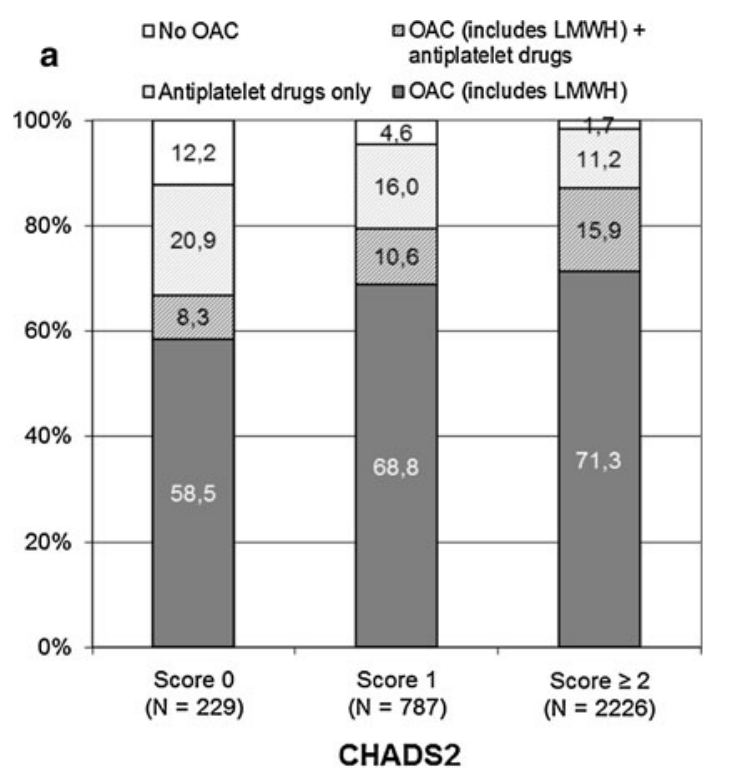

Table 4 Pharmacological and electrical conversions

\begin{tabular}{lll}
\hline & $n$ & $\%$ \\
\hline Pharmacological (drug) conversion & 855 & 23.3 \\
Ambulatory & 351 & 41.1 \\
Hospital based & 454 & 53.1 \\
Ambulatory/hospital based & 26 & 3.0 \\
Unknown & 24 & 2.8 \\
Number of drug conversions & & \\
1 & 540 & 63.2 \\
2 & 165 & 19.3 \\
3 & 36 & 4.2 \\
4 & 18 & 2.1 \\
5 & 6 & 0.7 \\
6 & 6 & 0.7 \\
7 & 3 & 0.4 \\
8 & 8 & 0.5 \\
9 & 1 & 0.1 \\
$10+$ & 9 & 1.0 \\
Unknown & 67 & 7.8
\end{tabular}

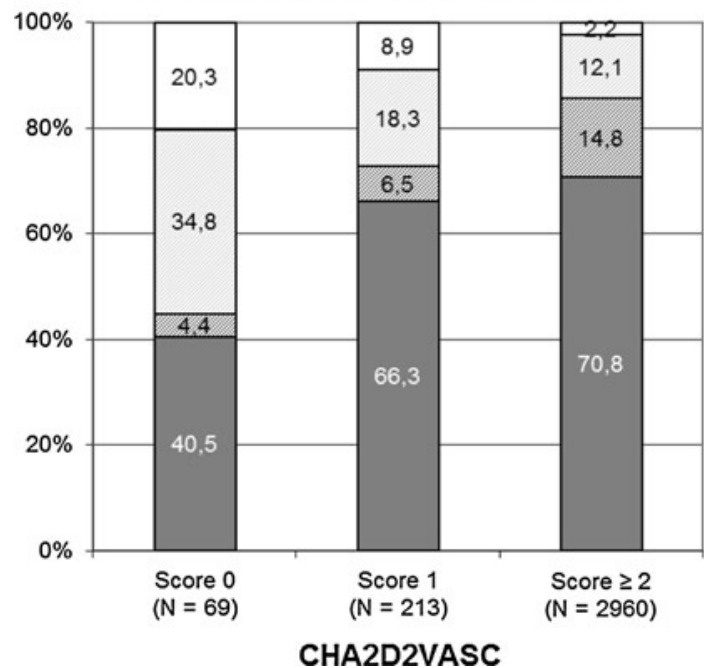

Fig. 3 Antithrombotic prophylaxis and oral anticoagulation (OAC) in patients with various eligibility categories for OAC by CHADS2 or $\mathrm{CHA}_{2} \mathrm{DS}_{2}$-VASc. Score $O$ (=no risk factor $)=$ no OAC recommended; Score 1 (=only 1 non-major risk factor) = either ASS or OAC recommended, OAC preferred; Score $\geq 2$ (=at least 1 major or at least 2 non-major risk factors) $=\mathrm{OAC}$ recommended. Information on antithrombotic prophylaxis and oral anticoagulation was missing in 409 patients

permanent nature of AF render the number of patients with hospitalizations and "unstable disease" in our cohort remarkable, especially when this number was compared to the markedly lower hospitalization rate (about 25-27\%) in large, recently published trials in $\mathrm{AF}$ patients such as ADONIS/EURIDIS [29], ATHENA [10] and RACE II [32]. While it is conceivable that lower hospitalization rates in trials reflect a selection bias toward "healthier" patients and
Duration since last conversion (months); $n=794^{\mathrm{a}}$

$\begin{array}{llr}\text { Mean } \pm \text { SD } & 27.4 \pm 40.5 & \\ \text { Median } & 11.0 & \\ \text { Range } & 0.0-340.0 & \\ \text { Electrical conversion } & 820 & 22.4 \\ \text { Ambulatory } & 62 & 7.6 \\ \text { Hospital based } & 684 & 83.4 \\ \text { Ambulatory/hospital based } & 4 & 0.5 \\ \text { Unknown } & 70 & 8.5 \\ \text { Number of electrical conversions } & & \\ 1 & 482 & 58.8 \\ 2 & 171 & 20.9 \\ 3 & 59 & 7.2 \\ 4 & 19 & 2.3 \\ 5 & 2 & 0.2 \\ 6+ & 7 & 0.8 \\ \text { Unknown } & 80 & 9.8\end{array}$

Duration since last conversion (months); $n=751^{\mathrm{a}}$

$\begin{array}{llr}\text { Mean } \pm \text { SD } & 30.3 \pm 37.8 & \\ \text { Median } & 14.0 & \\ \text { Range } & 0.0-286.0 & \\ \text { Catheter ablation } & 194 & 5.3 \\ \text { Implantation of pacemaker/defibrillators } & 384 & 10.5\end{array}$

Data from 3,367 patients

$S D$ standard deviation

a Subpopulation with information on duration since last conversion

possibly better overall management owing to the close follow-up regimen in clinical trials, the reasons for hospitalizations in this "all-comer" population with long-standing $\mathrm{AF}$ are worthy of further study. 
Table 5 Hospitalizations

\begin{tabular}{llr}
\hline & $n$ & $\%$ \\
\hline Number & & \\
0 & 2,015 & 54.9 \\
1 & 830 & 22.6 \\
2 & 341 & 9.3 \\
3 & 185 & 5.0 \\
4 & 110 & 3.0 \\
5 & 54 & 1.5 \\
$6+$ & 82 & 2.2 \\
Unknown & 50 & 1.4 \\
Number of hospitalizations & Mean \pm SD; median \\
Total $(n=3,617)$ & $1.0 \pm 1.9 ;$ range $0-61$ \\
Paroxysmal $(n=978)$ & $1.2 \pm 1.7^{\#}$ & \\
Persistent $(n=937)$ & $1.1 \pm 1.8^{\#}$ & \\
Permanent $(n=1,512)$ & $0.7 \pm 2.0^{\#}$ & \\
Rhythm control $(n=185)$ & $1.5 \pm 2.0$ \\
Rate control $(n=2,728)$ & $0.8 \pm 1.8$ \\
Rhythm + rate control $(n=401)$ & $1.8 \pm 2.1$ \\
\hline
\end{tabular}

\# $p<0.0001$ for comparison of means by $F$ test (analysis of variance/ANOVA)

Methodological considerations In selecting centers, care was taken to represent all regions in Germany equally. Nonetheless, it is conceivable that there remained a selection bias for centers with interest and/or expertise in AF management associated with the agreement to participate. Further limitations of this study are possible reporting bias (e.g., underreporting of diseases by physicians), misclassification of disease (e.g., AF type), selection bias of patients (only those willing to participate), neglect of patient-related factors such as treatment compliance and patient recall bias (e.g., on number of procedures or hospitalizations in the previous 12 months). Despite the systematic process for selecting participating centers (see "Methods"), selection bias of participating physicians is also possible. Furthermore, it was not possible to verify consecutive enrollment or the completeness of the information on the paper CRF by source data monitoring.

\section{Conclusion}

ATRIUM provides a hitherto unknown insight into details of current AF management in primary care in Germany. The good overall antithrombotic management is remarkable, but the frequent AF-related hospitalizations and the overall, often unstable, course of AF indicate unsolved problems. Challenges in the treatment of AF in these often multimorbid patients (with high rates of coronary artery disease and hypertension, for example) pose challenges to treating physicians.
Acknowledgments ATRIUM was funded by Sanofi-Aventis, Germany. LR is an employee of Sanofi-Aventis, and the other authors have received honoraria from Sanofi-Aventis for research and advice. A full list of financial disclosures for PK is available on the Web site of the ESC.

Open Access This article is distributed under the terms of the Creative Commons Attribution Noncommercial License which permits any noncommercial use, distribution, and reproduction in any medium, provided the original author(s) and source are credited.

\section{References}

1. Camm AJ, Kirchhof P, Lip GY, Schotten U, Savelieva I, Ernst S et al (2010) Guidelines for the management of atrial fibrillation: The Task Force for the Management of Atrial Fibrillation of the European Society of Cardiology (ESC). Eur Heart J 31:2369-2429

2. Carlsson J, Tebbe U, Rox J, Harmjanz D, Haerten K, Neuhaus KL et al (1996) Cardioversion of atrial fibrillation in the elderly. ALKK-Study Group. Arbeitsgemeinschaft Leitender Kardiologischer Krankenhausaerzte. Am J Cardiol 78:1380-1384

3. Friberg J, Scharling H, Gadsboll N, Jensen GB (2003) Sex-specific increase in the prevalence of atrial fibrillation (The Copenhagen City Heart Study). Am J Cardiol 92:1419-1423

4. Frykman V, Beerman B, Ryden L, Rosenqvist M (2001) Management of atrial fibrillation: discrepancy between guideline recommendations and actual practice exposes patients to risk for complications. Eur Heart J 22:1954-1959

5. Fuster V, Ryden LE, Asinger RW, Cannom DS, Crijns HJ, Frye RL et al (2001) ACC/AHA/ESC guidelines for the management of patients with atrial fibrillation: executive summary. A report of the American College of Cardiology/American Heart Association Task Force on Practice Guidelines and the European Society of Cardiology Committee for Practice Guidelines and Policy Conferences (Committee to Develop Guidelines for the Management of Patients With Atrial Fibrillation) developed in collaboration with the North American Society of pacing and electrophysiology. Circulation 104:2118-2150

6. Go AS, Hylek EM, Phillips KA, Chang Y, Henault LE, Selby JV et al (2001) Prevalence of diagnosed atrial fibrillation in adults: national implications for rhythm management and stroke prevention: the AnTicoagulation and Risk Factors In Atrial Fibrillation (ATRIA) study. JAMA 285:2370-2375

7. Goudevenos JA, Vakalis JN, Giogiakas V, Lathridou P, Katsouras C, Michalis LK et al (1999) An epidemiological study of symptomatic paroxysmal atrial fibrillation in northwest Greece. Europace 1:226-233

8. Granada J, Uribe W, Chyou PH, Maassen K, Vierkant R, Smith PN et al (2000) Incidence and predictors of atrial flutter in the general population. J Am Coll Cardiol 36:2242-2246

9. Greiner W, Claes C, Busschbach JJ, von der Schulenburg JM (2005) Validating the EQ-5D with time trade off for the German population. Eur J Health Econ 6:124-130

10. Hohnloser SH, Crijns HJGM, van Eickels M, Gaudin C, Page RL, Torp-Pedersen $\mathrm{C}$ et al (2009) Effect of dronedarone on cardiovascular events in atrial fibrillation. N Engl J Med 360:668-678

11. Hohnloser SH, Kuck KH, Lilienthal J (2000) Rhythm or rate control in atrial fibrillation-pharmacological Intervention in atrial fibrillation (PIAF): a randomised trial. Lancet 356:1789-1794

12. Kannel WB, Wolf PA, Benjamin EJ, Levy D (1998) Prevalence, incidence, prognosis, and predisposing conditions for atrial fibrillation: population-based estimates. Am J Cardiol 82:2N-9N 
13. Kerr CR, Boone J, Connolly SJ, Dorian P, Green M, Klein G et al (1998) The Canadian Registry of atrial fibrillation: a noninterventional follow-up of patients after the first diagnosis of atrial fibrillation. Am J Cardiol 82:82N-85N

14. Kirch W, Pittrow D, Bosch R, Kohlhaußen A, Willich SR, Bonnemeier H (2010) Gesundheitsbezogene Lebensqualität bei Patienten mit Vorhofflimmern in der kardiologischen Versorgung: MOVE-Studie. Deutsche Med Wochenschr 135(Suppl 2)

15. Kompentenznetz Vorhofflimmern (AF-NET). http://www. kompetenznetz-vorhofflimmern.de/aktuelles/2008/10/1690.php. Accessed 27 Sept 2010

16. Krahn AD, Manfreda J, Tate RB, Mathewson FA, Cuddy TE (1995) The natural history of atrial fibrillation: incidence, risk factors, and prognosis in the Manitoba follow-up study. Am J Med 98:476-484

17. Le Heuzey J, Breithardt G, Camm J, Crijns H, Dorian P, Kowey P et al (2010) The record AF study: design, baseline data, and profile of patients according to chosen treatment strategy for atrial fibrillation. Am J Cardiol 105:687-693

18. Le Heuzey JY, Paziaud O, Piot O, Said MA, Copie X, Lavergne $\mathrm{T}$ et al (2004) Cost of care distribution in atrial fibrillation patients: the COCAF study. Am Heart J 147:121-126

19. Levy S, Maarek M, Coumel P, Guize L, Lekieffre J, Medvedowsky JL et al (1999) Characterization of different subsets of atrial fibrillation in general practice in France: the ALFA study. The College of French Cardiologists. Circulation 99:3028-3035

20. Lip GY, Golding DJ, Nazir M, Beevers DG, Child DL, Fletcher RI (1997) A survey of atrial fibrillation in general practice: the West Birmingham Atrial Fibrillation Project. Br J Gen Pract 47:285-289

21. Lip GY, Nieuwlaat R, Pisters R, Lane DA, Crijns HJ (2010) Refining clinical risk stratification for predicting stroke and thromboembolism in atrial fibrillation using a novel risk factorbased approach: the Euro Heart Survey on Atrial Fibrillation. Chest 137:263-272

22. Majeed A, Moser K, Carroll K (2001) Trends in the prevalence and management of atrial fibrillation in general practice in England and Wales, 1994-1998: analysis of data from the general practice research database. Heart 86:284-288

23. Nabauer M, Gerth A, Limbourg T, Schneider S, Oeff M, Kirchhof $P$ et al (2009) The Registry of the German Competence NETwork on atrial fibrillation: patient characteristics and initial management. Europace 11:423-434

24. Nieuwlaat R, Capucci A, Camm AJ, Olsson SB, Andresen D, Davies DW et al (2005) Atrial fibrillation management: a prospective survey in ESC Member Countries: the Euro Heart Survey on atrial fibrillation. Eur Heart J 26:2422-2434

25. Nieuwlaat R, Olsson SB, Lip GY, Camm AJ, Breithardt G, Capucci A et al (2007) Guideline-adherent antithrombotic treatment is associated with improved outcomes compared with undertreatment in high-risk patients with atrial fibrillation. The Euro Heart Survey on atrial fibrillation. Am Heart J 153:1006-1012

26. Roy D, Talajic M, Nattel S, Wyse DG, Dorian P, Lee KL et al (2008) Rhythm control versus rate control for atrial fibrillation and heart failure. N Engl J Med 358:2667-2677

27. Santini M, De Ferrari GM, Pandozi C, Alboni P, Capucci A, Disertori $M$ et al (2004) Atrial fibrillation requiring urgent medical care. Approach and outcome in the various departments of admission. Data from the atrial Fibrillation/flutter Italian REgistry (FIRE). Ital Heart J 5:205-213

28. Singer DE, Albers GW, Dalen JE, Fang MC, Go AS, Halperin JL et al (2008) Antithrombotic therapy in atrial fibrillation: American College of chest physicians evidence-based clinical practice guidelines, 8th edn. Chest 133:546S-592S

29. Singh BN, Connolly SJ, Crijns HJ, Roy D, Kowey PR, Capucci A et al (2007) Dronedarone for maintenance of sinus rhythm in atrial fibrillation or flutter. N Engl J Med 357:987-999

30. Stewart S, Hart CL, Hole DJ, McMurray JJ (2001) Population prevalence, incidence, and predictors of atrial fibrillation in the Renfrew/Paisley study. Heart 86:516-521

31. Valderrama AL, Dunbar SB, Mensah GA (2005) Atrial fibrillation: public health implications. Am J Prev Med 29:75-80

32. Van Gelder IC, Groenveld HF, Crijns HJGM, Tuininga YS, Tijssen JGP, Alings AM et al (2011) Lenient versus strict rate control in patients with atrial fibrillation. $\mathrm{N}$ Engl $\mathrm{J}$ Med 362:1363-1373

33. Van Gelder IC, Hagens VE, Bosker HA, Kingma JH, Kamp O, Kingma $T$ et al (2002) A comparison of rate control and rhythm control in patients with recurrent persistent atrial fibrillation. N Engl J Med 347:1834-1840

34. Vidaillet H, Granada JF, Chyou PH, Maassen K, Ortiz M, Pulido JN et al (2002) A population-based study of mortality among patients with atrial fibrillation or flutter. Am J Med 113:365-370

35. Wandell PE (2001) A survey of subjects with present or previous atrial fibrillation in a Swedish community. Scand J Prim Health Care 19:20-24

36. Wang TJ, Larson MG, Levy D, Vasan RS, Leip EP, Wolf PA et al (2003) Temporal relations of atrial fibrillation and congestive heart failure and their joint influence on mortality: the Framingham Heart Study. Circulation 107:2920-2925

37. Wattigney WA, Mensah GA, Croft JB (2003) Increasing trends in hospitalization for atrial fibrillation in the United States, 1985 through 1999: implications for primary prevention. Circulation 108:711-716

38. Wyse DG (2005) The Euro Heart Survey on atrial fibrillation: a picture and a thousand words. Eur Heart J 26:2356-2357

39. Wyse DG, Waldo AL, DiMarco JP, Domanski MJ, Rosenberg Y, Schron EB et al (2002) A comparison of rate control and rhythm control in patients with atrial fibrillation. $\mathrm{N}$ Engl $\mathrm{J}$ Med 347:1825-1833 